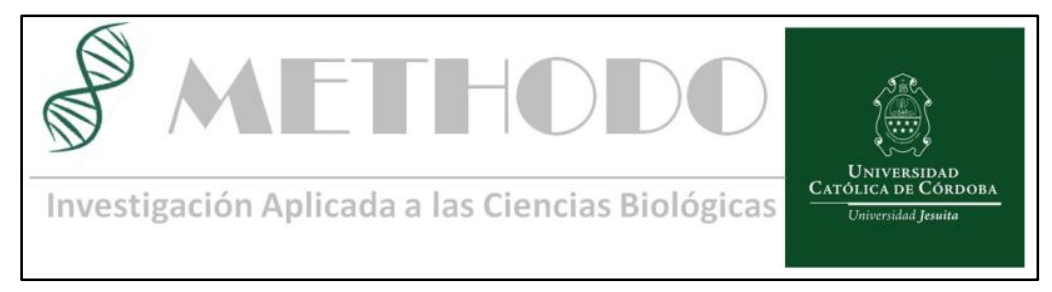

EDITORIAL

Recibido 03 Oct 2016 | Aceptado 03 Oct 2016 | Publicado 01 Dic 2016

\title{
METHODO: palabra griega compuesta
}

Iniciamos con este primer número de la Revista METHODO un espacio para la publicación de investigaciones vinculadas a las ciencias biológicas.

METHODO, palabra griega que, se origina de la unión de dos términos META + HODO.

Meta significa más allá y hodo camino, ahora reunidas podríamos interpretar como "camino para llegar más allá...."; probablemente uno de los primeros "metodólogos" haya sido René Descartes cuando propone el método cartesiano como una manera de avanzar en la búsqueda de la verdad y evitar el error en el origen del conocimiento, como consecuencia de una reflexión desordenada donde se da como supuesto lo que se debe justificar. Descartes escribió: "es mejor no buscar la verdad que hacerlo sin método". (1)

Esta publicación intentará ser un instrumento que sirva para la expresión científica en sus distintos aspectos, está pensado para artículos originales, revisiones temáticas, casos clínicos, temas de bioética, tips en investigación, resúmenes de tesis doctorales, de cualquier área de las ciencias biológicas y de esta manera favorecer la "visibilidad" del conocimiento producido por los autores que confíen en nosotros sus publicaciones.

Como dice el pedagogo alemán Winfried Böhm (2) "la diferencia entre una escuela y una universidad es que la primera usa el conocimiento y la segunda lo origina", por lo que generar conocimiento es una de las funciones sociales de la Universidad. Una vez producido debe ponerse a disposición de la sociedad en general y del mundo del saber en particular.

El conocimiento científico, al cual se debe facilitar el acceso, adquiere sentido cuando tiene como objetivo la vida del hombre y de su comunidad, de esta forma queremos posicionar el compromiso institucional con el saber poniendo a disposición nuestro instrumento de divulgación científica.

Esperamos, todos los que de alguna forma participamos de esta Revista, 
puedan disfrutar y encontrar en este instrumento una herramienta que favorezca el hacer científico profesional.

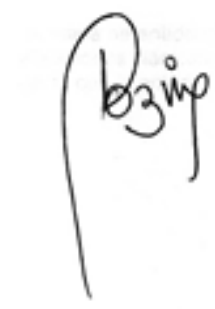

Alejandro Lozano

Editor

(1) Muñoz G, López A. Cuestiones Bibliográficas sobre el Método Cartesiano. Revista General de Información y documentación. 1995; 5 (1): 71-82

(2) Böhm W. La Universidad entre crisis y esperanza. Simposio Universitario. 2000 